\title{
Optimum Inclination Angles of Booster Mirrors and Solar Radiation Availability on the Horizontal and Inclined Box Type Solar Cookers
}

\author{
V. P. Sethi ${ }^{1}$, K. Sumathy ${ }^{2}$, D. S. Pal ${ }^{3}$ \\ ${ }^{1}$ Department of Mechanical Engineering, Punjab Agricultural University, Ludhiana, Punjab India; ${ }^{2}$ Department of Mechanical Engi- \\ neering, North Dakota State University, Fargo, USA; ${ }^{3}$ Department of Mathematics, Statistics and Physics, Punjab Agricultural Uni- \\ versity, Ludhiana, Punjab India. \\ Email: vpsethi@pau.edu
}

Received October 2013

\begin{abstract}
Mathematical relations are developed to compute optimum inclination angle of booster mirror for horizontally placed cooker $(\lambda)$ and for optimally inclined cooker $(\psi)$ during all months (selected day) of the year at $30^{\circ} \mathrm{N}$ latitude for maximizing the reflected component of solar intensity onto the absorber plate of the cooker. A solar radiation model is also developed and used to compute the ratio of various solar intensities on horizontal, inclined and normal surface of the absorber plate for all months at $30^{\circ} \mathrm{N}$ latitude. These ratios give a clear indication of greater solar radiation availability on the optimally inclined cooker as compared to the horizontally placed cooker for faster cooking especially during winter months when solar radiation capture is small. Experimental validations have also been performed to access the accuracy of the developed relations and model.
\end{abstract}

Keywords: Solar Radiation; Solar Cooker; Optimum Inclination; Booster Mirror

\section{Introduction}

Many important modular studies have been performed on box type solar cookers till date to optimize their performance. Transient analysis was performed to get the overall thermal performance of the box type solar cooker by [1]. A box type solar cooker which could perform well in clear sunny days was developed [2]. An oblique pan was also designed for putting the food material in tilted position. Parametric study of box type solar cooker was also performed with and without booster mirrors called reflectors [3]. Thermal performance of box type solar cooker was tested and a test procedure was developed to test its performance using two figures of merit $\mathrm{F}_{1}$ and $\mathrm{F}_{2}$ [4].

An improved box type solar cooker with tilted absorbing surface was developed but the problem of placing the food material could not be solved [5]. Methods of testing and evaluating the advanced version of the box-type solar cooker were also developed [6]. A model for prediction of the cooking power of a solar cooker based on three controlled parameters (solar intercept area, overall heat loss coefficient, and absorber plate thermal conductivity) and three uncontrolled variables (insolation, temperature difference, and load distribution) was developed [7]. The performance of solar cookers by analyzing the previously collected data was also evaluated [8]. The role of cooking vessel inside the cooker was established taking into consideration its lid and the bottom surface [9, 10]. Cooking vessel design in cylindrical shape of box type was also improved and its heat transfer from the lid was also made faster to the food material placed inside the vessel [11,12]. A comparative experimental study of a box type solar cooker with two different cooking vessels was made [13]. Fins are shown to improve the heat transfer from the internal hot air of the cooker towards the interior of the vessel where the food to be cooked is placed. An optimally inclined box type solar cooker with modified cooking vessel design was presented [14]. The performance of optimally inclined cooker was consistently better as compared to conventional horizontally placed cooker in terms of higher solar radiation availability, absorber plate temperature, higher chamber temperature and lesser cooking time.

The review reveals that various researchers around the world have developed many improved solar cooker designs either by increasing the aperture (solar interception area), by using multiple reflectors, by changing the inclination of the solar cookers, by reducing the overall heat transfer coefficient, by increasing the conductive heat transfer of absorber plate and by modifying the cooking 
vessel design. In this study, a mathematical model is developed to compute the optimum inclination angle of the booster mirror for horizontally placed and inclined cooker for maximizing the reflected component of the solar radiation for better performance during all months and selected latitudes.

\section{Description of Horizontal and Inclined Box Type Solar Cookers}

Two identical box type solar cookers of length $580 \mathrm{~mm}$, width $300 \mathrm{~mm}$ and height $155 \mathrm{~mm}$ each were fabricated using galvanized iron sheet of $0.8 \mathrm{~mm}$ thickness. One cooker was kept in horizontal position on ground (Figure 1) while the other cooker was kept on an optimally inclined frame (Figure 2) in inclined position. Each cooker has two top glass covers of $4 \mathrm{~mm}$ thickness and a booster mirror with a provision of altering the angle of inclination. A round shape cylindrical cooking vessel of $175 \mathrm{~mm}$ diameter and $52 \mathrm{~mm}$ depth was placed inside the horizontally placed cooker. The designed parallelepiped cooking vessel was placed horizontally inside the inclined cooker for greater heat transfer to the food material.

\section{Mathematical Model for Optimum Tilt Angle of the Booster Mirrors}

\subsection{Horizontally Placed Cooker}

Optimum tilt angle of the booster mirror is computed for all months and given latitude for maximizing the reflected radiation component onto the absorber plate.

In Figure 1, at the top edge A of the booster mirror

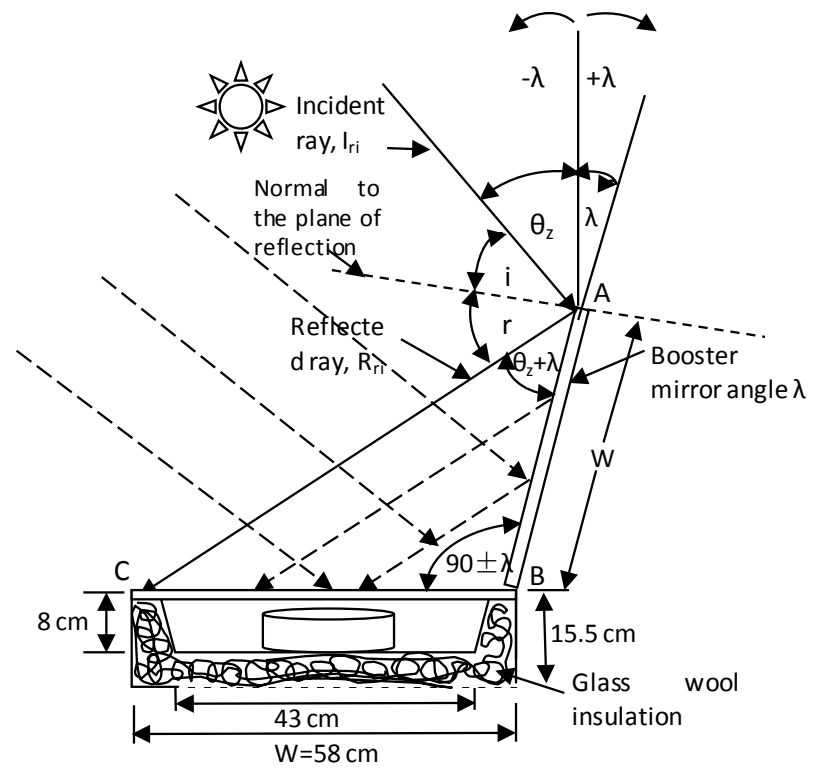

Figure 1. Horizontal cooker with booster mirror at optimum inclined angle $\lambda$.

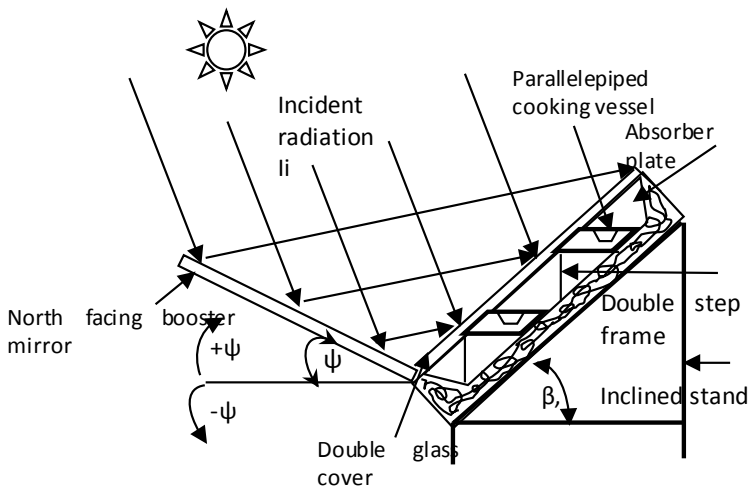

Figure 2. Inclined cooker with booster mirror at optimum inclined angle $\psi$.

$$
\begin{gathered}
\lambda+\theta_{z}+i=90^{\circ} \\
\text { also } \angle C A B+r=90^{\circ}
\end{gathered}
$$

from Equations (1) and (2)

$$
\angle C A B=\lambda+\theta_{z}
$$

If ray $I_{r 1}$ strikes the top of the inclined reflector mirror at an angle $\lambda+\theta_{z}$, then the line AC formed by reflected ray $\mathrm{R}_{\mathrm{r} 1}$ reaching the edge of the upper glass cover also has the same internal angle $\lambda+\theta_{z}$, then in triangle $\mathrm{ABC}$;

$$
\begin{aligned}
& \angle C A B=\theta_{z}+\lambda, \angle A B C=90^{\circ} \pm \lambda \\
& \text { and } \angle A C B=90^{\circ}-2 \lambda-\theta_{z}
\end{aligned}
$$

Also mathematically we know that

$$
\frac{B C}{\sin \left(\theta_{z}+\lambda\right)}=\frac{A B}{\sin \left(90^{\circ}-2 \lambda-\theta_{z}\right)}=\frac{A C}{\sin \left(90^{\circ} \pm \lambda\right)}
$$

Since $\mathrm{AB}=\mathrm{BC}=\mathrm{W}$ (width of the absorber plate)

$$
\frac{W}{\sin \left(\theta_{z}+\lambda\right)}=\frac{W}{\sin \left(90^{\circ}-2 \lambda-\theta_{z}\right)}
$$

Equation (5) gives the value of optimum tilt angle of the booster mirror $\lambda$ for horizontally placed cooker;

$$
\lambda=\frac{90^{\circ}-2 \theta_{z}}{3}
$$

\subsection{Optimum Tilt Angle of the Booster Mirror for Inclined Cooker}

Optimum tilt of the booster mirror $(\psi)$ in case of north facing reflector (Figure 2) of inclined solar water heater was given by [15] and is used for inclined cooker as

$$
\psi=(\pi-\beta-2 \phi+2 \delta) / 3
$$

The declination angle " $\delta$ " is computed using the given Equation (8)

$$
\delta=23.45 \sin \left[\frac{360(284+n)}{365}\right]
$$


where " $n$ " is the number of days starting from January 1.

\section{Solar Radiation Model}

Variation of effective width of the sun rays intercepted by the absorber plate in horizontal and inclined position of the cooker is shown in Figures 3(a) and (b).

In $\triangle \mathrm{ABC}$

$$
\begin{gathered}
\angle A=90-\alpha_{s} \\
W_{h}=W \times \cos \left(90-\alpha_{s}\right)
\end{gathered}
$$

Where $\alpha_{s}$ can be computed using Equation (15).

Hourly solar radiation incident on the inclined surface of the absorber plate depends upon the time of the day i.e. the hour angle $\omega$ (zero at noon, negative in the morning and positive in afternoon, varies by $15^{\circ}$ after each hour), $n^{\text {th }}$ day of the year (starts from January 1 ) i.e. declination angle $\delta$, altitude angle $\alpha_{\mathrm{s}}$ with horizontal or zenith angle $\theta_{z}$ with vertical and surface azimuth angle $\gamma$ (in northern hemisphere, it is zero for south facing surfaces, $180^{\circ}$ for north facing surfaces, $-90^{\circ}$ for east facing and +90 for west facing surfaces), latitude angle $\phi$ of a place and tilt angle $\beta$ of the surface with horizontal.

Zenith angle of sun on the inclined absorber plate $\theta_{i}$ is given by [16]

$$
\begin{aligned}
\theta_{i}=\cos ^{-1}[ & \sin f(\sin \delta \cos \beta+\cos \delta \cos g \cos \omega \sin \beta) \\
& +\cos f(\cos \delta \cos \omega \cos \beta-\sin \delta \cos g \sin \beta) \\
& +\cos \delta \sin g \sin \omega \sin \beta]
\end{aligned}
$$

Zenith angle of the sun with vertical $\left(\theta_{z}\right)$ and solar altitude angle $\left(\alpha_{s}\right)$ with horizontal at any time of the day and for any day of the year can be determined at any specific latitude location is given by [16].

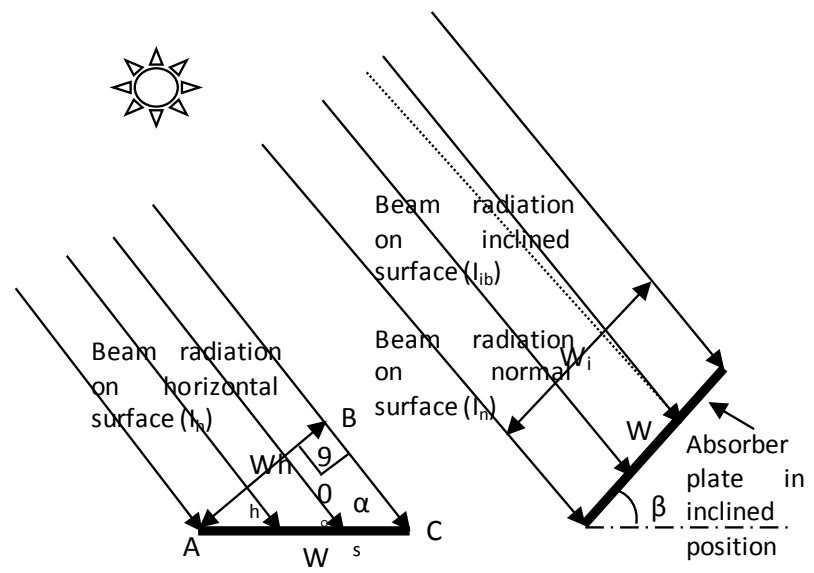

(a)

(b)

Figure 3. Variation of effective width of the sun rays intercepted by the absorber plate in (a) horizontal and (b) inclined position.

$$
\begin{gathered}
\theta_{z}=\cos ^{-1}(\cos \phi \cdot \cos \delta \cdot \cos \omega+\sin \delta \cdot \sin \phi) \\
\omega=15^{\circ}\left(t_{\text {solar }}-12\right)
\end{gathered}
$$

The hour angle is $15^{\circ}$ times the number of hours from solar noon. It is negative before noon, zero at noon and positive after 12 .

Intensity of extra terrestrial radiation $I_{e x t}$ measured on a plane normal to the radiation on the $n^{\text {th }}$ day of the year,

$$
I_{\text {ext }}=I_{s c}\left[1+0.034 \cos \left(\frac{360 n}{365}\right)\right]
$$

Value of direct normal solar radiation in terrestrial region depends upon turbidity factor $T_{r}$ of atmosphere [17].

$$
I_{n}=I_{e x t} \times \exp \left[\frac{-T_{r}}{0.9+9.4 \sin \alpha_{s}}\right]
$$

$T_{r}$ is known for different months and for different regions [18].

$$
\begin{aligned}
\alpha_{\mathrm{s}} & =90-\theta_{z} \\
I_{b}{ }^{\prime} & =I_{n} \cos \theta_{i} \\
I_{h b} & =I_{n} \cos \theta_{z}
\end{aligned}
$$

The amount of diffuse radiation available on the inclined surface can be known as (Tiwari, 2006)

$$
\begin{gathered}
I_{d}{ }^{\prime}=I_{d}\left[\frac{I_{b}{ }^{\prime} \cos \theta_{i}}{I_{e x t} \sin \alpha_{s}}+\left(1-\frac{I_{b}{ }^{\prime}}{I_{\text {ext }}}\right) \cos ^{2} \beta / 2\right] \\
I_{d}=\frac{1}{3}\left(I_{\text {ext }}-I_{n}\right) \cos \theta_{z}
\end{gathered}
$$

The reflected component of total radiation is then computed as

$$
I_{R}{ }^{\prime}=r I_{g h} \sin ^{2} \beta / 2
$$

Where " $r$ " is the ground reflectivity (0.3)

$$
\mathrm{I}_{\mathrm{gh}}=I_{b}+I_{d}
$$

On the horizontal surface of the absorber plate at solar noon.

Total solar radiation falling on the inclined surface of the absorber plate at solar noon is given by

$$
I_{i}=I_{b}{ }^{\prime}+I_{d}{ }^{\prime}+I_{R}{ }^{\prime}
$$

A computer program in $\mathrm{C}^{++}$is developed and used for computing the solar radiation flux on various surfaces.

\section{Results and Discussion}

\subsection{Optimum Tilt Angles}

Optimum tilt angles computed for winter and summer months at $30^{\circ} \mathrm{N}$ latitude are shown in Table 1. It shows 
that for horizontal cooker, optimum inclination angle $\lambda$ is $3.3^{\circ}, 1.2^{\circ}$ and $8.2^{\circ}$ outwards $(+)$ from the vertical position $\left(\lambda=0^{\circ}\right)$ in October, February and March. It becomes $2.08^{\circ}, 5.6^{\circ}$ and $4.2^{\circ}$ inwards (-) from the vertical position during November, December and January due to greater solar zenith angle $\left(\theta_{z}\right)$. During summer, optimum inclination angle $\lambda$ is $20.8^{\circ}, 11.2^{\circ}, 6.8^{\circ}, 8.9^{\circ}, 16.7^{\circ}$ and $27.6^{\circ}$. In the case of inclined cooker, the optimum inclination angle $\psi$ in winter months is $18.5^{\circ}, 12.1^{\circ}, 9.4^{\circ}, 11.0^{\circ} 16.3^{\circ}$ and $23.3^{\circ}$. This variation is much higher in summer months as $41.5^{\circ}, 47.6^{\circ}, 50.6^{\circ}, 49.2^{\circ}, 44^{\circ}$ and $36.2^{\circ}$ for maximization of reflected component.

\subsection{Solar Radiation Capture Ratios}

The ratio $W_{h} / W_{i}$ is $0.62,0.73,0.84,0.76,0.65$ and 0.60 during January, February, March, October, November and December which shows that intercepted width for solar radiation capture is much smaller for horizontal cooker as compared to inclined cooker. The ratio of solar radiation intensity available on inclined to horizontal cooker $\left(I_{i} / I_{g h}\right)$ is 1.51, 1.33, 1.15, 1.26, 1.45 and 1.66 during January, February, March, October, November and Decem- ber which shows that inclined cooker receives much higher solar radiation intensity as compared to horizontal cooker in winter months. The variation of horizontal versus normal surface and inclined versus normal surface also shows that inclined cooker receives almost maximum possible radiation during all months of the year as the ratio is always close to one. Whereas for horizontal cooker this variation is 0.59 to 1.00 during winter and summer months.

\subsection{Experimental Validation}

The Figure 4 shows that the measured and predicted values of solar radiation intensities match well for horizontal as well as for inclined surface of absorber plate within $5 \%$ of the standard deviation. It shows that the developed model is accurate enough for making correct predictions for solar radiation availabilities at optimized inclination angles.

Finally it can be concluded that inclined cooker has much better solar radiation capture during winter months for efficient cooking as compared to horizontally placed cooker at $30^{\circ} \mathrm{N}$ latitude.

Table 1. Optimum tilt angles computed for horizontal $(\lambda)$ and inclined cooker $(\psi)$ at $30^{\circ} \mathrm{N}$ latitude during all months of the year.

\begin{tabular}{ccccccccc}
\hline Winter Month and date, (n) & \multicolumn{3}{c}{ Latitude $\left({ }^{\circ} \mathrm{N}\right) 30$} & Summer Month and date, (n) & \multicolumn{3}{c}{ Latitude $\left({ }^{\circ} \mathrm{N}\right) 30$} \\
\hline & $\theta_{\mathrm{z}}$ & $\lambda$ & $\psi$ & & $\theta_{\mathrm{z}}$ & $\lambda$ & $\psi$ \\
\hline Oct. 15, (288) & 40.1 & 03.3 & 18.5 & Apl, 15, (105) & 20.8 & 16.1 & 41.5 \\
Nov. 15, (319) & 49.3 & -2.08 & 12.1 & May 15, (135) & 11.2 & 22.5 & 47.6 \\
Dec. 15, (349) & 53.5 & -5.6 & 9.4 & June 15, (166) & 6.8 & 25.5 & 50.6 \\
Jan. 15, (15) & 51.3 & -4.2 & 11.0 & July 15, (196) & 8.9 & 24.0 & 49.2 \\
Feb. 15, (46) & 43.2 & 1.2 & 16.3 & Aug. 15, (227) & 16.7 & 18.8 & 44.0 \\
Mar. 15, (74) & 32.7 & 8.2 & 23.3 & Sept. 15, (258) & 27.6 & 11.4 & 36.2 \\
\hline
\end{tabular}

Table 2. Shows the ratios of intercepted widths for horizontal $\left(W_{h}\right)$ and inclined cooker $\left(W_{i}\right)$ and solar radiation intensities on Horizontal $\left(I_{g h}\right)$, Inclined $\left(I_{i}\right)$ and normal $\left(I_{n}\right)$ surfaces for horizontal and inclined cookers at $30^{\circ} \mathrm{N}$ latitude during all months of year.

\begin{tabular}{|c|c|c|c|c|c|c|c|c|c|}
\hline \multirow[t]{2}{*}{ Month and date, $\left(T_{r}\right)$} & \multicolumn{4}{|c|}{ Latitude $30^{\circ} \mathrm{N}$} & \multirow[t]{2}{*}{ Month and date, $\left(T_{r}\right)$} & \multicolumn{4}{|c|}{ Latitude $30^{\circ} \mathrm{N}$} \\
\hline & $W_{h} / W_{i}$ & $I_{i} / I_{g h}$ & $I_{h b} / I_{n}$ & $I_{b^{\prime}} / I_{n}$ & & $W_{h} / W_{i}$ & $I_{i} / I_{g h}$ & $I_{h b} / I_{n}$ & $I_{b^{\prime}} / I_{n}$ \\
\hline Jan. 15, (3.1) & 0.62 & 1.51 & 0.62 & 0.99 & July 15, (4.3) & 1.00 & 1.00 & 0.99 & 0.99 \\
\hline Feb. 15, (3.2) & 0.73 & 1.33 & 0.73 & 1.00 & Aug. 15, (4.2) & 0.95 & 1.04 & 0.96 & 0.99 \\
\hline Mar. 15, (3.5) & 0.84 & 1.15 & 0.84 & 1.00 & Spt. 15, (3.9) & 0.88 & 1.08 & 0.88 & 0.97 \\
\hline Apl, 15, (3.9) & 0.93 & 1.05 & 0.93 & 1.00 & Oct. 15, (3.6) & 0.76 & 1.26 & 0.76 & 0.98 \\
\hline May 15, (4.1) & 0.98 & 1.02 & 0.98 & 1.00 & Nov. 15, (3.3) & 0.65 & 1.45 & 0.65 & 0.99 \\
\hline June 15, (4.2) & 1.00 & 1.00 & 0.99 & 0.99 & Dec. 15, (3.1) & 0.60 & 1.66 & 0.59 & 0.99 \\
\hline
\end{tabular}




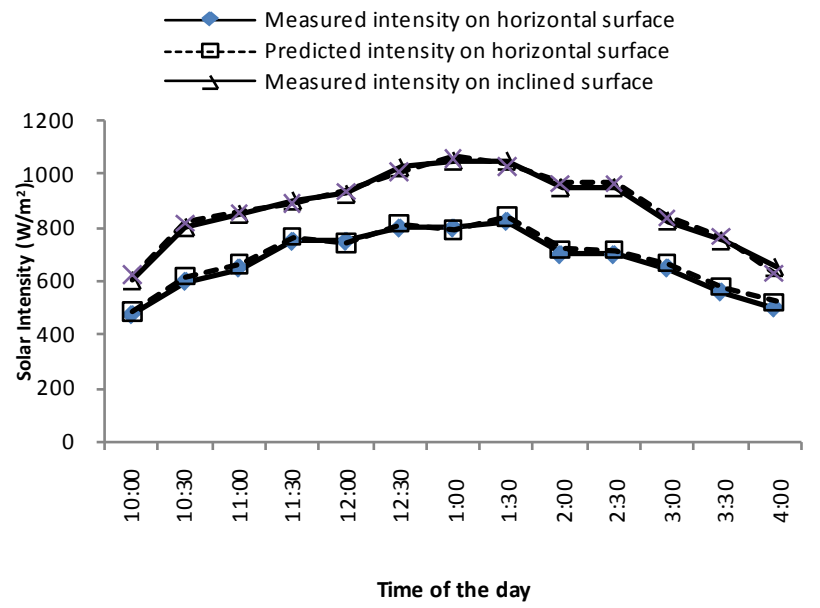

Figure 4. Measured and predicted solar radiation intensities on the horizontal and inclined surfaces of absorber plate on $15^{\text {th }}$ March, 2012.

\section{REFERENCES}

[1] Y. S. Yadav and G. N. Tiwari, "Transient Analytical Study of Box-Type Solar Cooker," Energy Conversion and Management, Vol. 27, No. 3, 1987, pp. 121-125. http://dx.doi.org/10.1016/0196-8904(87)90064-1

[2] P. C. Pande and K. P. Thanvi, "Design and Development of a Solar Cooker for Maximum Energy Capture in Stationary Mode," Energy Conversion and Management, Vol. 27, 1987, pp. 117-120. http://dx.doi.org/10.1016/0196-8904(87)90062-8

[3] B. A. Jubran and M. A. Alsaad, "Parametric Study of Box-Type Solar Cooker," Energy Conversion and Management, Vol. 32, 1987, pp. 223-234. http://dx.doi.org/10.1016/0196-8904(91)90126-4

[4] S. C. Mullick, T. C. Khandpal and A. K. Saxena, "Thermal Test Procedures for Box Type Solar Cooker,” Solar Energy, Vol. 39, 1987, pp. 353-360. http://dx.doi.org/10.1016/S0038-092X(87)80021-X

[5] N. M. Nahar, "Performance and Testing of an Improved Hot Box Solar Cooker," Energy Conversion and Management, Vol. 30, 1990, pp. 9-16. http://dx.doi.org/10.1016/0196-8904(90)90051-Y

[6] M. Grupp, P. Montagne and M. Wackennagel, “A Novel Advanced Box Type Solar Cooker,” Solar Energy, Vol. 47, 1991, pp. 107-113. http://dx.doi.org/10.1016/0038-092X(91)90041-T
[7] P. A. Funk and D. L. Larson, "Parametric Model of Solar Cooker Performance,” Solar Energy, Vol. 62, No. 1, 1998, pp. 63-68.

[8] P. A. Funk, "Evaluating the International Standard Procedure for Testing Solar Cookers and Reporting Performance,” Solar Energy, Vol. 68, No. 1, 2000, pp. 1-7.

[9] R. A. V. Narasimha and S. Subramanyam, "Solar CookersPart I: Cooking Vessel on Lugs,” Solar Energy, Vol. 75, No. 3, 2003, pp. 181-185.

[10] R. A. V. Narasimha and S. Subramanyam, "Solar CookersPart II: Cooking Vessel with Central Annular Cavity,” Solar Energy, Vol. 78, No. 1, 2005, pp. 19-22.

[11] A. R. Reddy and R. A. V. Narasimha, "Prediction and Experimental Verification of Performance of Box Type Solar Cooker-Part I. Cooking Vessel with Central Cylindrical Cavity,” Energy Conversion and Management, Vol. 48, No. 7, 2007, pp. 2034-2043.

[12] A. R. Reddy and R. A. V. Narasimha, "Prediction and Experiemental Verification of Performance of Box Type Solar Cooker-Part II. Cooking Vessel with Depressed Lid,” Energy Conversion and Management, Vol. 49, 2008, pp. 240-246. http://dx.doi.org/10.1016/j.enconman.2007.06.020

[13] A. Harmim, M. Boukar and M. Amar, "Experimental Study of a Double Exposure Solar Cooker with Finned Cooking Vessel," Solar Energy, Vol. 82, No. 4, 2008, pp. 287-289.

[14] V. P. Sethi and S. Kumar, "Inclined Box Type Solar Cooker Using Modified Absorber Plate and New Cooking Vessel Design,” Proceedings of International Conference on Recent Innovations in Technology, Kottayam, Kerala, 12-14 January 2012, pp. 233-237.

[15] S. P. Sukhatme, "Solar Energy, Principles of Thermal Collection and Storage,” 6th Edition, Tata McGraw-Hill Publishing Company Limited, New Delhi, 1990.

[16] J. A. Duffie and W. A. Beckman, "Solar Engineering of Thermal Processes,” John Wiley and Sons, New York, 1991.

[17] G. N. Tiwari, "Solar Energy Fundamentals, Design, Modelling and Applications," Narosa Publishing House, New Delhi, 2006.

[18] N. K. Bansal, M. Kleeman and M. Meliss, "Renewable Energy Sources and Conversion Technology,” Tata McGraw Hill Publishing Co., New Delhi, 1990. 